\title{
Detecção de foco de incêndio subterrâneo em turfa por câmera portátil termal
}

\author{
Detection of Underground Fire in Peat Soil by Means Portable Thermal Camera
}

\author{
André Matos Pinto Cota ${ }^{1,2}$ \\ Gustavo Macedo de Mello Baptista ${ }^{2}$
}

\author{
${ }^{1}$ Corpo de Bombeiros Militar do Distrito Federal - CBMDF - 70610-200 - Brasília- DF. \\ 2 Instituto de Geociências, Universidade de Brasília - UnB. Campus Darcy Ribeiro - Caixa Postal 4465 - $70910-900$ - \\ Asa Norte - Brasília- DF. \\ andrempcota@gmail.com,gmbaptista@unb.br
}

Artigo - Submissão: 06/05/2015 - Aceito em: 14/12/2015

\begin{abstract}
RESUMO - Os incêndios subterrâneos em turfa ocorrem na região de campos úmidos no Bioma do cerrado do DF na época da estiagem. Geralmente se iniciam após um incêndio superficial e apresentam comportamento extremamente devastador para o ecossistema local e principalmente para o solo. Nos períodos de estiagem no cerrado a severidade da queima pode ser tão grande, que se não controlado em seu princípio, pode perdurar por longos períodos e só será possível a sua extinção com a chegada das chuvas no início da estação chuvosa. A detecção dos focos deste tipo incêndio não é simples de visualizar no espectro visível, pois ocorrem no subsolo, além de que andar em um terreno instável para identificar focos não é seguro. Assim, utilizou-se um radiômetro que opera no infravermelho termal para observar a sua eficiência na detecção dos focos em incêndios reais em uma APA. Foram obtidas imagens após o controle do incêndio superficial e aéreas no dia seguinte à ocorrência, pela manhã. Observou-se que é nítida na identificação dos focos os padrões de comportamento de queima igual aos experimentos realizados por outros pesquisadores, assim como a geração das imagens aéreas permitem gerar um rápido reconhecimento para que as equipes de combate em solo. A utilização do sensor termal possibilitou a rápida detecção, assim provendo as equipes de combate rápida ação para a extinção do incêndio.
\end{abstract}

Palavras-chave: Turfa, Incêndio Subterrâneo, Radiômetro Termal.

ABSTRACT - The underground peat fires occur in the region of swamps in the Cerrado Biome of the Distrito Federal in the dry season. Usually starting after a surface fire and being extremely devastating to the local ecosystem and especially to the soil. Its severity can become so great that if not controlled the fires can burn until the first rains put them out. The detection of fire outbreaks of this type are not easy to see in the visible spectrum, because they occur in the subsoil, and to walk with fire under the feet to identify outbreaks is not safe. Therefore, we used a radiometer that operates in the long thermal infrared to observe its efficiency in detecting outbreaks in a real fire event that occurred in an Environmental Protection Area. Pictures in the soil after the control of the surface fire and aerial images on the following morning were obtained. It was observed that there is a clear identification of foci with behavior patterns of firing equal to experiments conducted by other researchers as well as to generate aerial images allow quick recognition for teams fighting on the ground. The use of thermal sensor enables rapid detection, thus providing the combat teams' quick action to extinguish the fire.

Keywords: Peat, Underground Fire, Thermal Radiometer.

\section{INTRODUÇÃO}

O cerrado faz limite com a floresta Atlântica e Amazônica, com as florestas da bacia do Paraná, com a Caatinga e o Pantanal, possuindo mais de 6.000 mil espécies em geral. Apresenta clima tropical com períodos de seca de aproximadamente cinco meses, podendo ficar com períodos de mais de 30 dias sem chuva. O fogo é um fator determinante para a caracterização das fisionomias naturais (UNESCO, 2002).

Encontram-se no Bioma do Cerrado alguns tipos vegetacionais associados a áreas úmidas. Na tabela 01 está relacionado a definição da vegetação natural do Distrito Federal e relacionado as áreas úmidas no Cerrado, segundo Eiten (2001).
Tabela 01 - Fitofisionomias associadas as áreas úmidas do Cerrado

\begin{tabular}{l|l}
\hline Fitofisionomia & Descrição \\
\hline \multirow{3}{*}{ Floresta de Galeria } & $\begin{array}{l}\text { Ocorrem margeando cursos } \\
\text { d'água, com solo sempre bem } \\
\text { drenado, estacional ou } \\
\text { permanentemente saturado. }\end{array}$ \\
\hline Campo Úmido & $\begin{array}{l}\text { Frequentemente forma uma faixa } \\
\text { horizontal sobre encostas de } \\
\text { vales, a qual separa o cerrado do } \\
\text { interflúvio da floresta-galeria do } \\
\text { fundo do vale. Durante a estação } \\
\text { chuvosa o lençol freático fica } \\
\text { próximo à superfície e aflora, já } \\
\text { durante a estação seca a porção }\end{array}$ \\
\hline
\end{tabular}




\begin{tabular}{l|l}
\hline & $\begin{array}{l}\text { superficial do solo mantém-se } \\
\text { seca. }\end{array}$ \\
\hline Campo de & $\begin{array}{l}\text { Campo úmido com montículos } \\
\text { naturais de terra em forma de } \\
\text { abóbada (murundus), com } \\
\text { cerrado nos seus topos. Os } \\
\text { murundus são, provavelmente, o } \\
\text { resultado de erosão diferencial } \\
\text { por escoamento superficial por } \\
\text { longo tempo. }\end{array}$ \\
\hline Veredas & $\begin{array}{l}\text { Uma unidade de vegetação } \\
\text { composta de faixas paralelas com } \\
\text { três tipos de vegetação diferentes, } \\
\text { lado a lado: campo úmido, brejo } \\
\text { permanente graminoso } \\
\text { buritizal. }\end{array}$ \\
\hline
\end{tabular}

Fonte: EITEN (2001).

As áreas úmidas do cerrado do Distrito Federal compreendem uma região de grande relevância ecológica para manutenção do equilíbrio biológico, bem como o equilíbrio do ciclo hidrológico na região do bioma do cerrado (DUGAN, 1990).

A turfa é um sedimento orgânico recente, formado a partir da decomposição parcial da matéria vegetal em um ambiente úmido, ácido e de pouca oxigenação (COUILLARD,1994). Ela faz parte do estágio inicial da formação do carvão mineral em decorrência da decomposição incompleta de material lenhoso, arbustivo, musgos e líquens nas áreas com muita umidade, desta forma a turfa está ligada a zonas alagadas (AGUIAR, 1987). Porém, a definição pode mudar dependendo do Estado ou Instituição, mas é consenso que turfa é um material que tem menos de $25 \%$ de massa inorgânica, com base na sua massa seca (ANDREJKO et al., 1983)

Segundo o IPT (1979), a formação dos depósitos de turfa ocorre de duas maneiras. Pela migração da vegetação ao redor de lagos ou lagoas para o centro, constituindo uma camada de plantas aquáticas que permite que outras plantas migrem para regiões mais estáveis nas margens do lago, assim ocorre o depósito de matéria orgânica morta na depressão desses lagos e lagoas conforme mostra a Fig. 01.

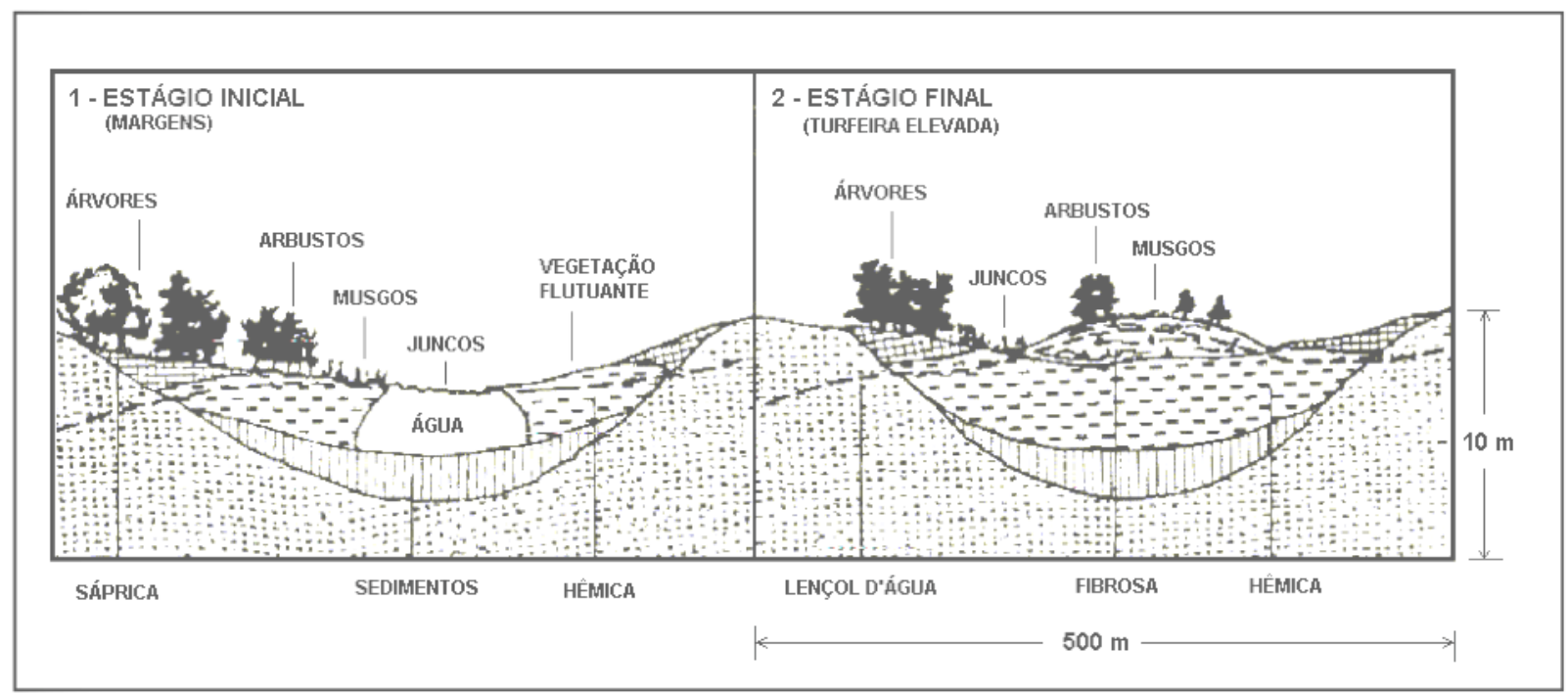

Figura 01 - Processo de formação de turfeiras em lagoas. Fonte: IPT (1979).

A segunda maneira ocorre por inundação constante de regiões de baixa drenagem que possa haver o acumulo de plantas mortas, folhas, galhos e outro tipo de matéria orgânica. Dessa forma, se dá o início do processo de acúmulo de material vegetal orgânico conforme Fig. 02.

A baixa oxigenação do solo, que por estar em meio aquoso, gera condições especiais para a decomposição da matéria orgânica, que devido ações de bactérias, fungos e outros microrganismos, levam a perdas dos vegetais originais, perda de oxigênio e hidrogênio, assim enriquecendo o carbono (IPT,1979).

Os incêndios florestais subterrâneos em turfa ocorrem no período de estiagem e provocam enormes danos ao ciclo biológico de fauna, flora, ao solo e por consequência aos recursos hídricos da região. Por ser subterrâneo, o foco deste tipo de incêndio florestal não é visível aos olhos de quem está na superfície (REIN, 2008). Eles queimam verticalmente e depois lateralmente. $\mathrm{O}$ processo da queima é mais intenso no subsolo do que na superfície já que o oxigênio disponível no interior do solo é maior que no perfil mais próximo da superfície devido o produto da queima inferior subir e ocupar o espaço do oxigênio na superfície (CHISTJAKOV, 1983).

Esses incêndios se propagam lentamente, sem chamas e causam severos danos físicos, químico e biológicos ao solo, podendo ocorrer em pequena ou grande proporção vindo até a destruir uma floresta inteira. A queima lenta e prolongada destrói raízes e sementes e gera enorme perda de biomassa na camada do solo. São incêndios que são difíceis de extinguir sem que haja chuvas fortes ou atendimento do Corpo de Bombeiro (REIN, 2008). 


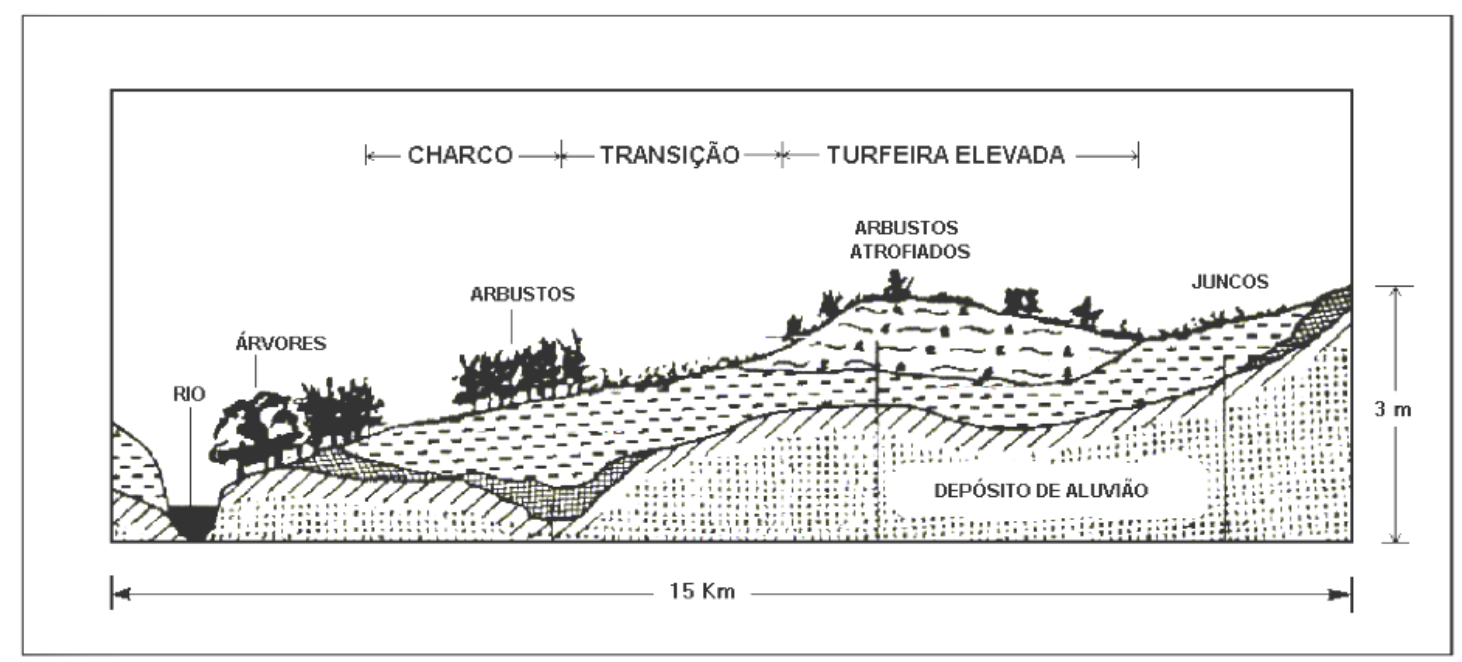

Figura 02 - Formação de turfeiras em áreas de inundação. Fonte: IPT (1979)

A perda de massa devido a queima da matéria orgânica e a evaporação da água pode ter uma variação de $20 \%$ até $75 \%$, assim após observar a região queimada notase que a camada visível do solo é marcada por alguns restos de matéria orgânica queimada ou por componentes minerais evitam a propagação (REIN, 2008).

Dois estudos serviram de fonte de comparação de dados para analisar com os valores obtidos em estudo de campo. Rein, (2008) realizou um ensaio em laboratório para detectar padrões de comportamento da combustão em turfa obtendo dados de temperatura, umidade, perda de matéria orgânica e outros. Usup, (2004) realizou um estudo em campo em pontos diversos em floresta de turfa numa temporada de estiagem obtendo dados que corroboraram com o de Rein, (2008).

No ensaio de Rein (2008) foram queimadas 25 amostras de turfa, com diferentes índices de umidade em uma caixa de $100 \mathrm{~mm} \times 100 \mathrm{~mm} \times 100 \mathrm{~mm}$. A caixa foi preenchida com o material até a altura de $50 \mathrm{~mm}$ e foram colocados 5 medidores de temperatura para avaliar a temperatura da turfa durante a queima, a severidade da ignição e a taxa de propagação. Assim os valores da temperatura foram registrados possibilitando estabelecer parâmetros para os momentos de pré queima, queima e pós queima.

Os experimentos mostraram que não houve ignição no material que possuía umidade maior que $35 \%$ e que nas queimas que a umidade variou entre 15 e $35 \%$ a propagação não passou dos $40 \mathrm{~mm}$ do ponto de ignição se extinguindo em 30 min e a temperatura não passou dos $450^{\circ} \mathrm{C}$ na região de combustão.

As temperaturas mais altas registradas variaram entre $400^{\circ} \mathrm{C}$ à $670^{\circ} \mathrm{C}$, sendo a mais alta em contato com o material gerador da ignição e nas áreas adjacente a ignição não se registrou temperatura superior a $80^{\circ} \mathrm{C}$ e nas regiões próximas ao ponto de combustão após terem sido queimadas não apresentaram temperatura superior a $100^{\circ}$ C.

Usup e colaboradores (2004) realizaram o experimento na floresta de turfas na região de Kilimatan da, Malásia, ao longo da rodovia Kilimatan durante a estiagem do ano de 2002. Foram escolhidos nove pontos que variam de 1 a $30 \mathrm{~km}$ de distância entre um e outro.

Foram usados sensores para medir a temperatura as profundidades de $0-20 \mathrm{~cm}, 20-40 \mathrm{~cm}$ e $40-60 \mathrm{~cm}$. Foi usada uma fonte externa para atingir a temperatura de $500^{\circ} \mathrm{C}$ como ignição. Assim, da mesma maneira que no ensaio de Rein, (2008) os dados aferidos pelos sensores de temperatura possibilitaram estabelecer os valores da pré queima, queima e pós queima. Desta forma, possibilita correlacionar os dados dos dois experimentos.

O experimento mostrou que a temperatura de ignição variou entre $340^{\circ} \mathrm{C}$ à $369^{\circ} \mathrm{C}$, já a temperatura das adjacências do foco não passou de $90^{\circ} \mathrm{C}$.

Tabela 02 - Característica da temperatura do foco de incêndio subterrâneo segundo os seguintes autores:

\begin{tabular}{|c|c|c|}
\hline Local & $\begin{array}{c}\text { Rein (2008) } \\
\text { Pesquisa em } \\
\text { laboratório }\end{array}$ & $\begin{array}{c}\text { Usup (2004) } \\
\text { Pesquisa em } \\
\text { Campo }\end{array}$ \\
\hline $\begin{array}{c}\text { Área da } \\
\text { combustão }\end{array}$ & $400^{\circ} \mathrm{C}$ à $670^{\circ}$ & $340^{\circ} \mathrm{C}$ à $369^{\circ} \mathrm{C}$ \\
\hline $\begin{array}{c}\text { Adjacências } \\
\text { a } \\
\text { combustão }\end{array}$ & $80^{\circ} \mathrm{C}$ à $100^{\circ} \mathrm{C}$ & Até $90^{\circ} \mathrm{C}$ \\
\hline
\end{tabular}

O objetivo desse trabalho foi analisar se a câmera portátil termal pode ajudar a realizar detecção de focos de incêndios subterrâneos em turfas de forma que o calor irradiado captado pelo sensor possa fornecer informações para a tomada de decisão das equipes que atuam no combate ao incêndio. A pesquisa foi realizada em ambiente real de incêndio subterrâneo, ou seja, as variáveis das condições ambientais nunca poderão ser repetidas, diferente de ensaios em laboratório, onde o ambiente pode ser preparado.

Partiu-se da hipótese que as informações obtidas na pesquisa de campo pudessem ser comparadas com os dados de duas pesquisas já realizadas, visto que ambas possuem os padrões de comportamento de incêndio em turfa bem similares e pode-se observar que os dados obtidos em 
campo também corroboraram com o comportamento da queima de turfa das pesquisas anteriores.

O emprego do equipamento permite que sejam realizados estudos não somente em incêndios subterrâneos em turfa, mas em outros tipos de substratos no solo como lodo de esgoto.

\section{MATERIAL E MÉTODOS}

\section{1 Área de estudo}

As três principais unidades de conservação da capital federal são o Parque Nacional de Brasília, a Estação Ecológica de Águas Emendadas e a APA (Área de Proteção Ambiental) Gama e Cabeça de Veado, que é constituída por três reservas: Fazenda Agua Limpa (FAL) da Universidade de Brasília (UNB), Reserva do Instituto Brasileiro de Geografia e Estatística (IBGE) e a Estação Ecológica do Jardim Botânico. Nestas áreas preservadas são realizadas inúmeras pesquisas sobre o cerrado (UNESCO, 2002).

A área de estudo foi escolhida em função da ocorrência de incêndio subterrâneo em área de turfa. No dia 12 de setembro de 2014, nas proximidades da Quadra 18/20 da região administrativa do Park Way, que se localiza dentro da Área de Proteção Ambiental Gama e Cabeça de Veado, teve início o incêndio florestal superficial que provocou o incêndio subterrâneo em turfa.

A área do estudo está localizada na bacia hidrográfica do Rio Paranoá, próximo ao limite oeste da Estação Ecológica do Jardim Botânico de Brasília que faz parte da Reserva da Biosfera do Cerrado e está dentro do Núcleo Rural Vargem Bonita que é considerado zona tampão da Reserva.

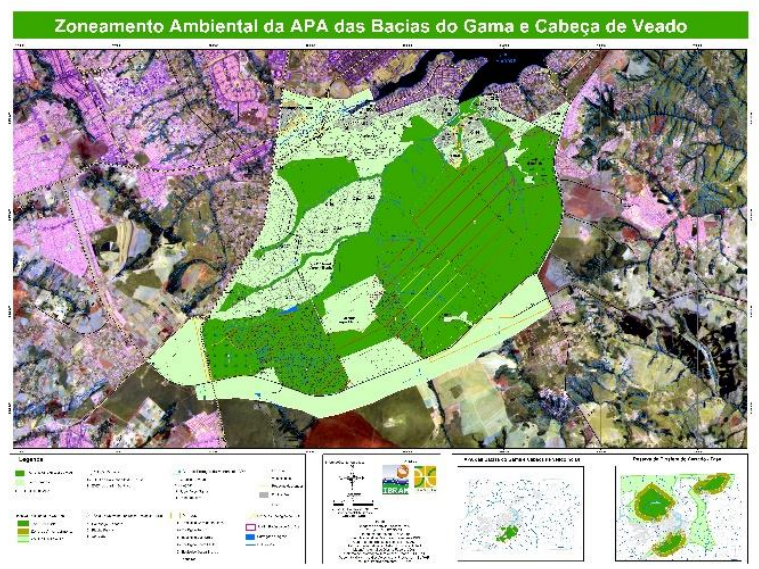

Figura 03 - Cartograma com a área de estudo. Fonte: IBRAM

\subsection{Equipamentos}

Foi utilizado o radiômetro modelo T4MAX Thermal Imager da Bullard, 320x240 pixel, não refrigerado e opera no espectro infravermelho de 7,5 $\mu \mathrm{m}-14 \mu \mathrm{m}$ para geração das imagens. O GPS Garmin, modelo 76CSx, acurácia menor de 10 metros, foi utilizado para identificar as coordenadas geográficas dos focos de incêndios subterrâneos, além de uma câmera digital Sony modelo DSC-W390, 14.1 megapixel. As imagens aéreas foram feitas a partir de um helicóptero modelo EC 135 da Airbus Helicopters.

O radiômetro T4MAX pesa aproximadamente 1,67 $\mathrm{Kg}$ com a bateria, suas imagens apresentam resolução de $320 \times 240$ pixels, seu alcance espectral varia entre 7,5 - 14,0 $\mu \mathrm{m}$, permitindo assim estabilidade termal na faixa de $-20^{\circ} \mathrm{C}$ até $85^{\circ} \mathrm{C}$ com variação sensitiva de $0,05^{\circ} \mathrm{C}$. Possui componentes eletrônicos para identifica temperaturas até $600^{\circ} \mathrm{C}$ com variação de erro de $25^{\circ} \mathrm{C}$.

A câmera portátil termal possui em seu visor uma barra lateral que é o indicador de temperatura relativa ITR. A precisão do indicador depende de alguns fatores como a sua distância do objeto, a emissividade do objeto. A precisão da temperatura diminui quando a distância do objeto ao sensor aumenta.

As especificações técnicas do radiômetro T4MAX descrevem que há três padrões de colorização da imagem, visando a segurança do operador. A imagem será disposta em amarelo para alertar temperaturas de $260^{\circ} \mathrm{C}$ até $426^{\circ} \mathrm{C}$, em alaranjado para temperaturas de $427^{\circ} \mathrm{C}$ até $537^{\circ} \mathrm{C}$ e em vermelho para temperaturas mais quentes que $538^{\circ} \mathrm{C}$. Esses padrões não podem ser alterados, pois são medidas de segurança para o usuário (BULLARD, 2013).

\subsection{Detecção dos Focos}

A localização de focos no subsolo foi realizada após o controle do incêndio superficial e se deu de forma visual, visando descartar as queimas de troncos, galhos, despejos de origem antrópica que ainda queimam na superfície, de forma sensitiva, pois o fluxo de calor emitido pelo solo permite que o operador do radiômetro T4MAX perceba as áreas mais quentes no corpo. Depois, com a utilização do radiômetro T4MAX pode-se verificar se o local observado apresentava padrões similares ao comportamento da queima realizada no experimento descrito por Rein (2008) e da experiência de campo de Usup (2004). Os focos localizados foram plotados utilizando as coordenadas obtidas com o GPS.

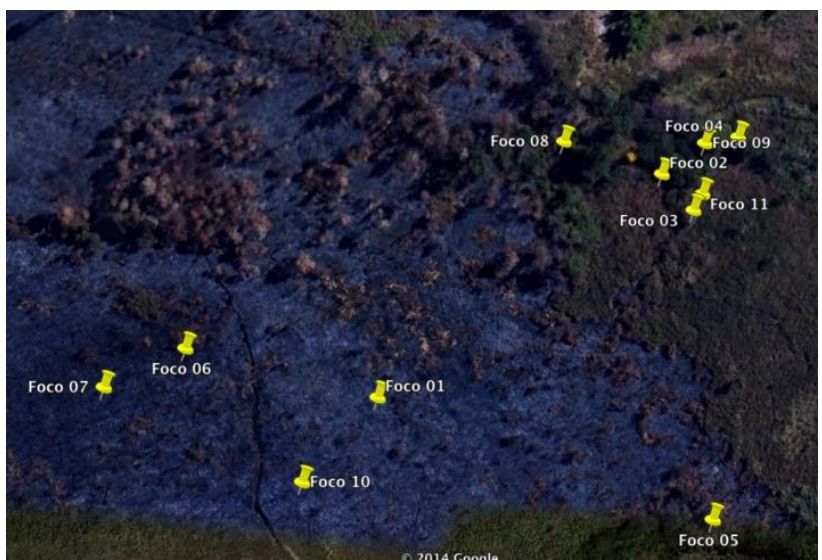

Figura 04 - Localização dos focos de incêndio subterrâneos. Fonte: Autor

A distância a ser utilizada entre o radiômetro T4MAX e o possível foco foi variável entre $1 \mathrm{~m}$ e a distância que 
operador possa se aproximar com segurança, devido à instabilidade do terreno, bem como o ângulo de visada entre sensor e alvo.

$\mathrm{O}$ radiômetro T4MAX também foi utilizado para gerar imagens aéreas por meio de sobrevoo de helicóptero sobre o local do evento a fim de verificar se as imagens geradas podem contribuir para realizar localização de focos de forma ampla. As imagens foram obtidas por meio do operador segurando o radiômetro T4MAX e captando as imagens com a aeronave no pairado, com portas abertas e a uma altura mínima que não entre no efeito solo gerado pelo fluxo de ar das pás do rotor e não gere deslocamento excessivo da fuligem acomodada no solo.

\section{RESULTADO E DISCUSSÃO}

\subsection{Analise das imagens}

\subsubsection{Condições do ambiente}

O incêndio superficial foi controlado por volta das 16 horas do dia 12 e posteriormente foi utilizado o radiômetro T4MAX para localizar os focos subterrâneos na área queimada. Foram identificados 11 focos, conforme mostra a Fig. 04. A atividade de detecção só pode ser realizada até o horário próximo ao pôr do sol, o que inviabilizou a localização de outros pontos devido não ser seguro andar no local sem a iluminação apropriada. A hora registrada nas imagens capturadas aparece com uma hora de atraso em relação ao horário oficial de Brasília.

A umidade relativa do ar aferida no dia do evento aferido pelo INMET era de aproximadamente $16 \%$ às 18 horas conforme registrado na estação meteorológica Brasília (Fig. 05). Observa-se que a umidade relativa do ar começa a decair a partir do dia 04 de setembro e tem o menor percentual no dia em que iniciou o incêndio subterrâneo, no dia 12. Essa constante queda na umidade relativa influencia na umidade superficial do solo e conforme descrito no estudo de Rein (2008), a queima na turfa não acontece com umidade no solo acima de $35 \%$ e que quanto menor a umidade do solo, maior a severidade da combustão da turfa.

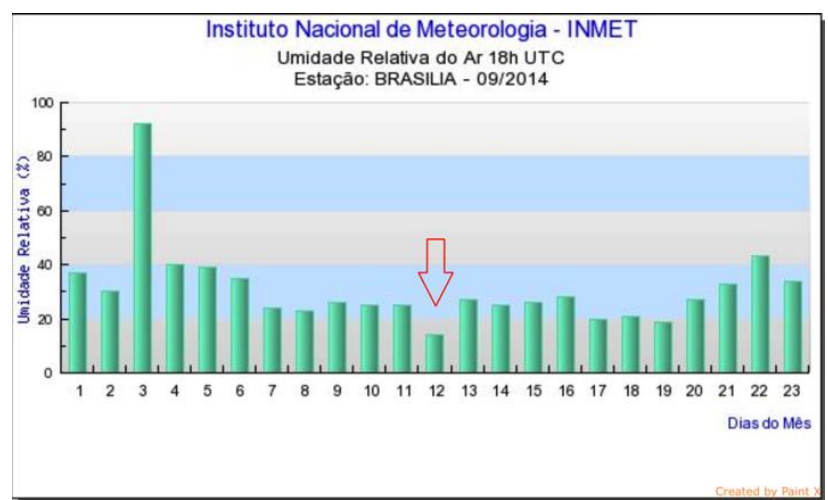

Figura 05 - Umidade relativa do ar. Fonte: INMET

\subsubsection{Imagens obtidas pelo operador no solo}

As Figuras 06 e 07 são imagens geradas do foco de incêndio subterrâneo. A Figura 06 mostra como o foco é visto no espectro visível, na qual não há nenhum indício visual da presença de foco de incêndio, nem as cinzas, que se confundem com a presença de matéria orgânica presente na turfa. A Figura 07 mostra a atividade térmica por meio do espectro do infravermelho termal. $\mathrm{O}$ alvo, localizado no centro da imagem e representado pelo sinal "+" na cor verde, indica a temperatura naquele ponto, que é mostrada na barra lateral da imagem. $\mathrm{O}$ alvo está sobre a região de cor vermelha, onde se aferiu temperatura superior à $450^{\circ} \mathrm{C}$. Compara-se com o ensaio de Rein (2008) no qual mostrou que a temperatura da queima da turfa varia entre $400^{\circ} \mathrm{C}$ à $670^{\circ} \mathrm{C}$ e nas suas regiões adjacentes não apresenta temperatura superior a $100^{\circ} \mathrm{C}$, ou seja, o comportamento se adequa aos ensaios realizados por Rein (2008) e Usup (2004).

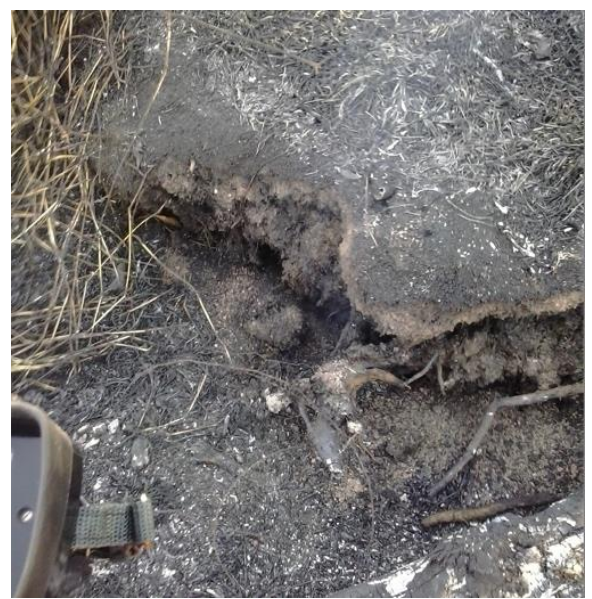

Figura 06 - Foco de incêndio subterrâneo (espectro visível). Fonte: Autor.

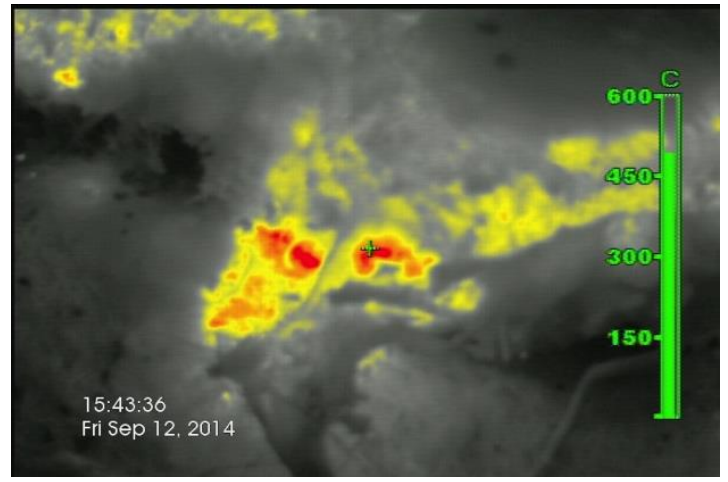

Figura 07 - Foco de incêndio subterrâneo (espectro termal). Fonte: Autor.

As Figuras 08, 09, e 10 são de outros focos de incêndio subterrâneo capturadas pela câmera digital no espectro visível. A Figura 08 mostra um foco no solo desnivelado, a Fig. 09, o foco no solo nivelado e na Fig. 10, o foco queimando a raiz de uma arvore. 


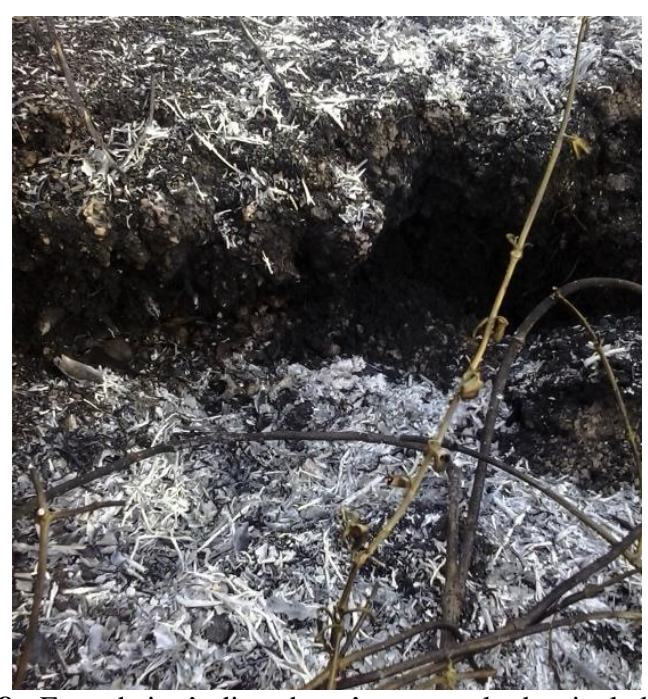

Figura 08 - Foco de incêndio subterrâneo no solo desnivelado. Fonte: Autor.

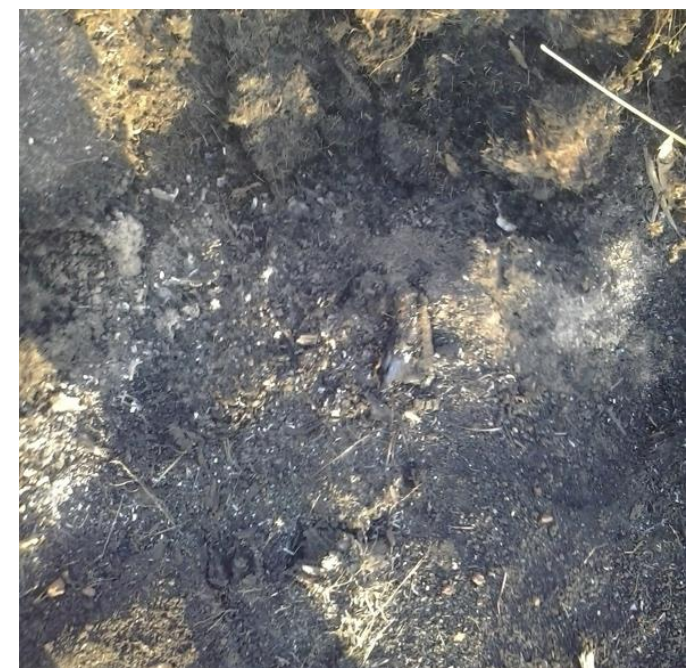

Figura 09 - Foco de incêndio subterrâneo no solo nivelado. Fonte: Autor.

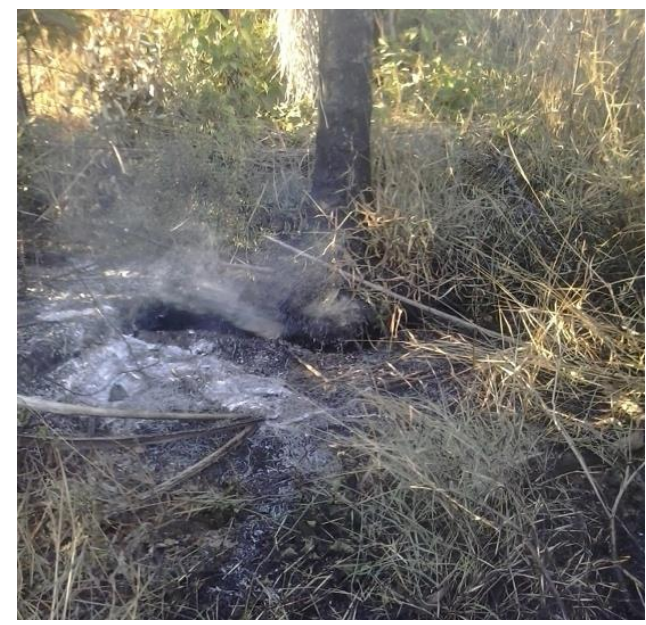

Figura 10 - Foco de incêndio subterrâneo em raiz de árvore. Fonte: Autor.

As Figuras 11, 12, 13, 14 e 15 foram obtidas nos focos de incêndio subterrâneo capturadas pelo radiômetro T4MAX. As Figuras 11 e 12 são focos de incêndio que ocorrem numa região de solo continuo, ou seja, não apresenta falhas ou desníveis, sendo possível observar temperaturas superiores a $400^{\circ} \mathrm{C}$ chegando a quase $600^{\circ} \mathrm{C}$.

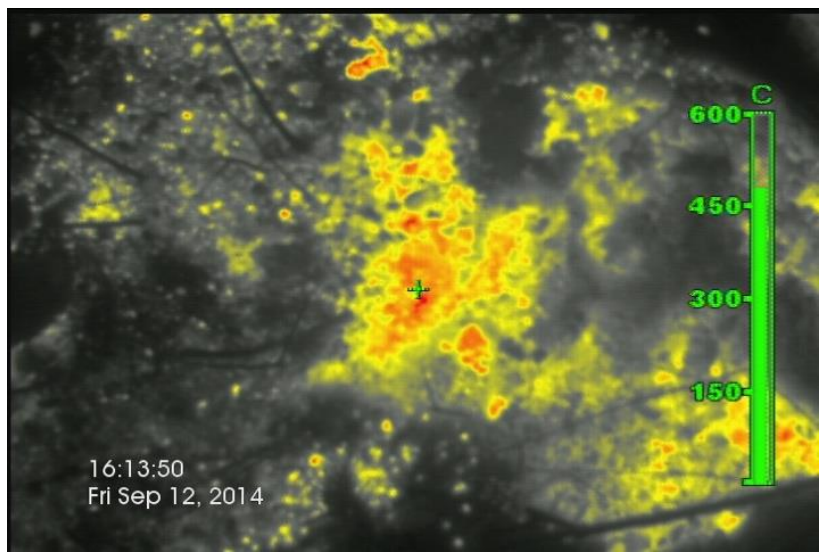

Figura 11 - Foco subterrâneo em solo nivelado e continuo. Fonte: Autor.

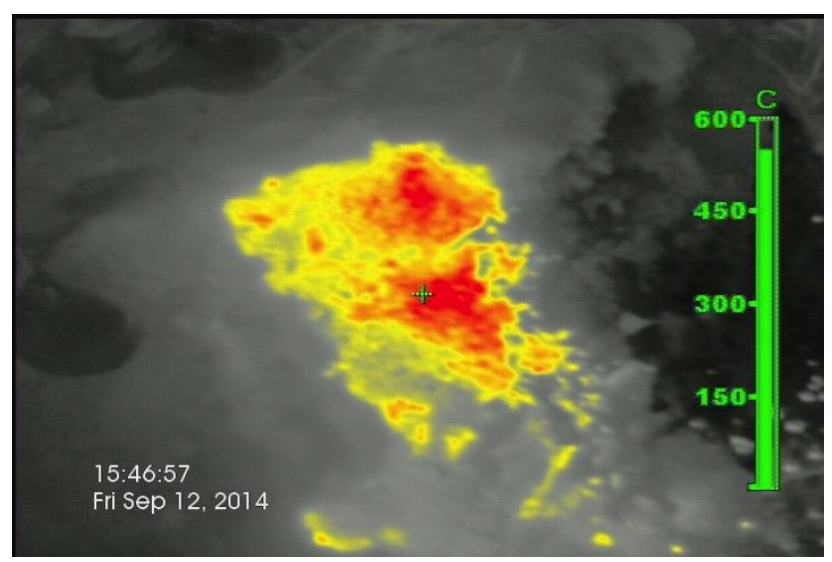

Figura 12 - Foco subterrâneo em solo nivelado e continuo. Fonte: Autor.

A Fig. 13 observa-se um foco no solo que apresenta um desnível sendo aplicado a visada angulada do radiômetro T4MAX.

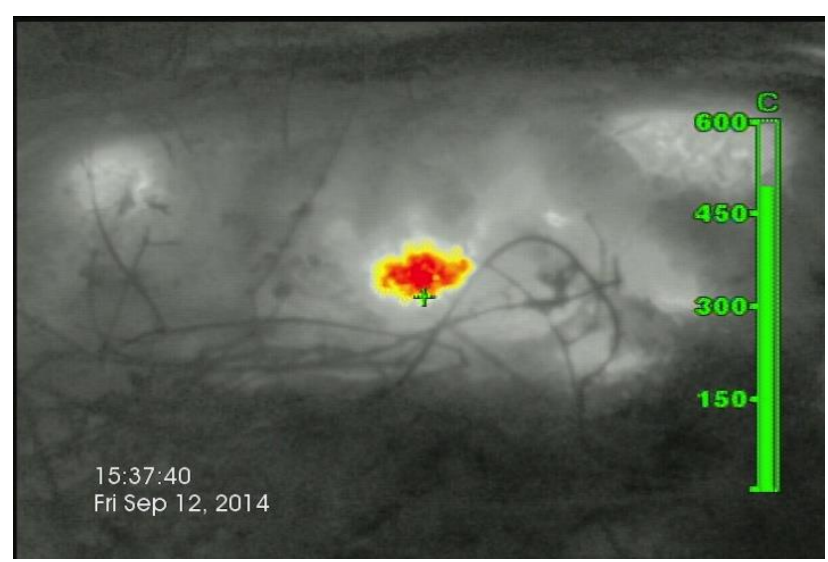

Figura 13 - Foco em solo desnivelado, visada angulada. Fonte: Autor.

Nas Figuras 14 e 15 o foco atingiu a raiz de uma árvore e que a queima apresenta temperatura superior a $400^{\circ} \mathrm{C}$ (Fig. 14) e na Figura 15 fica claro que logo na adjacência da queima a temperatura não passa dos $100^{\circ} \mathrm{C}$. 


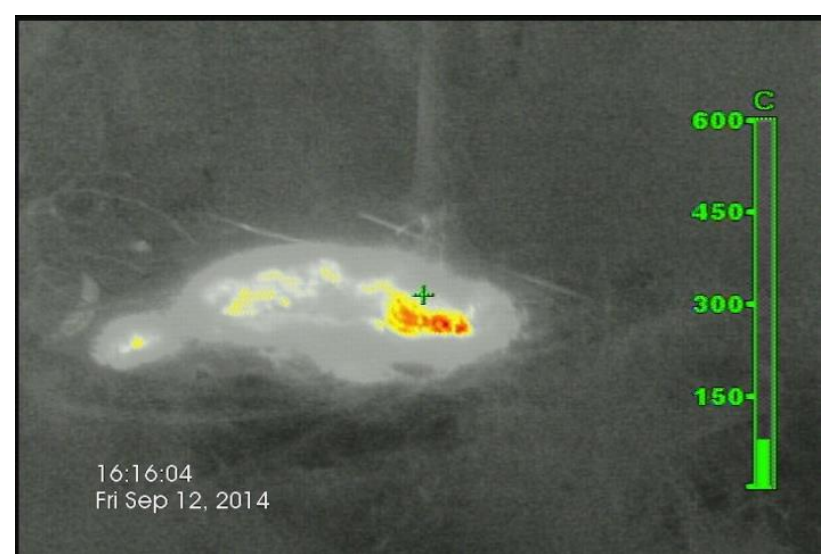

Figura 14 - Foco subterrâneo na raiz em uma árvore. Temperatura adjacente menor que $100^{\circ} \mathrm{C}$.

Fonte: Autor.

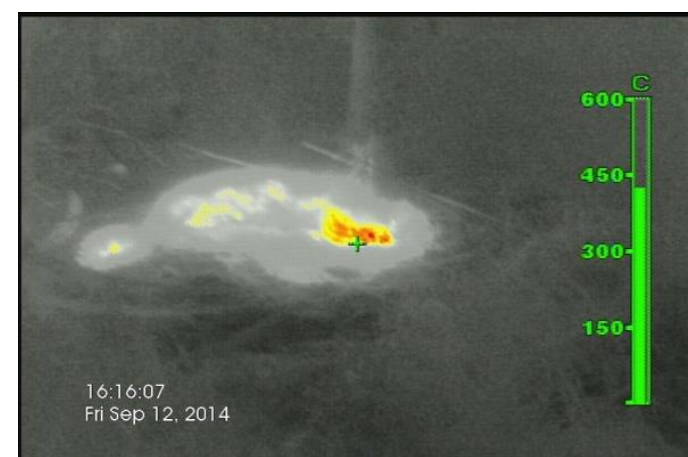

Figura 15 - Foco subterrâneo na raiz da árvore.

Fonte: Autor.

\subsubsection{Imagens obtidas pelo operador no ar}

As imagens aéreas foram obtidas por volta das 8 horas da manhã do dia seguinte ao início do incêndio. Foi possível detectar os focos e observar por meio de uma visão aérea a sua proximidade com áreas ainda não afetadas e deduzir como o incêndio tende a se propagar (Fig. 18). Porém, a uma distância que variou entre 8 e 12 metros não é possível visualizar os detalhes do foco, mas, em uma análise de um único foco, como mostra nas Fig. 16 e 17. O radiômetro T4MAX pode ser apontado para um local ao redor de um foco e o indicador de temperatura apresentara valor reduzido (Fig. 17), caso seja apontando para o centro do foco de incêndio é possível observar a elevação na temperatura (Fig. 16).

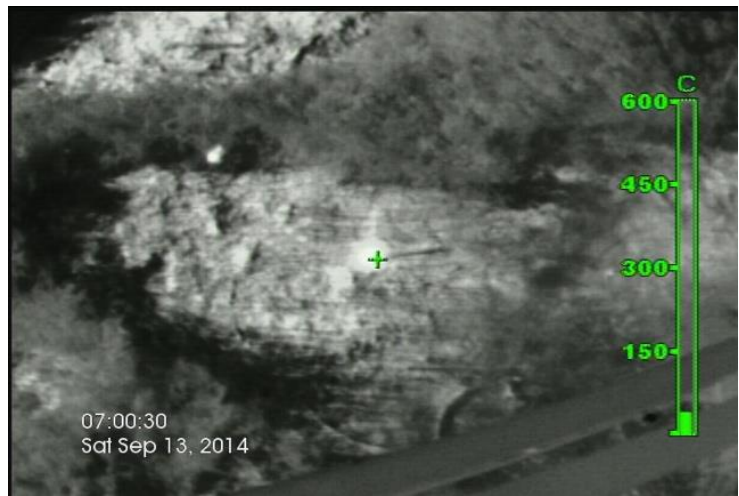

Figura 16 - Pontos quentes no incêndio obtida no sobrevoo. Fonte: Autor.

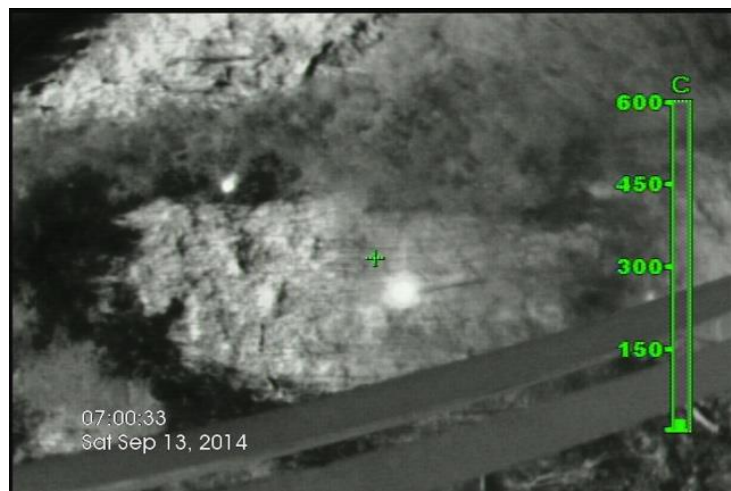

Figura 17 - Pontos adjacentes aos focos de incêndio. Fonte: Autor.

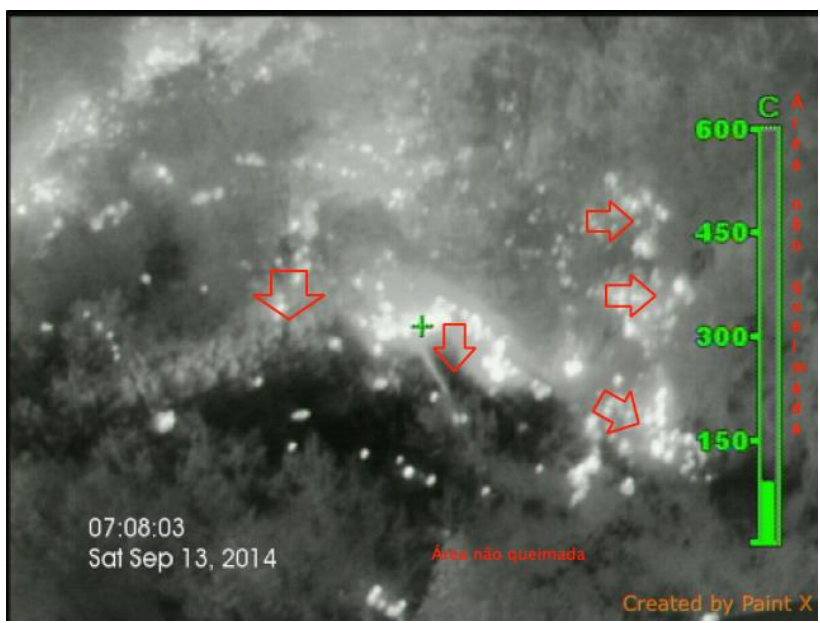

Figura 18 - Pontos quentes no incêndio e sentido da propagação Fonte: Autor.

Nas imagens aéreas torna-se mais difícil obter imagens com os padrões de queima dos estudos realizados, devido a distância do foco do incêndio para câmera portátil térmica, pois a definição de imagem do sensor é de $320 \times 240$ pixel. A altura da aeronave variou de 8 a 12 metros, assim cada pixel da imagem relata uma informação de uma área maior.

O sobrevoo na região, sem a iluminação urbana não pode ser realizado por fatores de segurança de voo, pois o helicóptero utilizado não é homologado para voo de instrumento, somente para voo visual, assim sem as luzes da cidade não há referência de altura de obstáculos do solo. O horário ideal para o sobrevoo foi o mais cedo possível para evitar que a energia de ondas curtas provenientes do Sol e refletidas para atmosfera pudessem criar interferências nas imagens. Outro fator são os ventos que no início do dia são mais fracos e propiciam voos menos turbulentos, assim evitando que as imagens borrem devido ao movimento transmitido da aeronave para o operador do instrumento. (JENSEN, 2008).

A análise de sensoriamento remoto termal neste estudo não ocorre com comparação entre dois objetos diferentes, mas sim somente do próprio solo com atividade de combustão ou sem atividade termal. 


\section{CONCLUSÃO}

As interpretações das imagens não devem ser realizadas unicamente por meio do sensor infravermelho. O conhecimento teórico sobre a dinâmica de incêndio subterrâneo em turfa e a observação da imagem gerada no espectro visível pelo olho do observador contribuem para que por meio da imagem da figura 6 seja inferido e comprovado que a linha formada pelos pontos mais claro refere-se à frente de queima no subsolo que avança para a área ainda não queimada. Assim o reconhecimento aéreo com o sensor de infravermelho pode definir áreas prioritárias de atuação para as equipes de combate ao incêndio atuem rapidamente nos focos do incêndio.

As áreas úmidas que pertencem ao bioma do cerrado são regiões sensíveis e de alta relevância para o ecossistema local e a preservação do ciclo hidrológico, assim a severidade do incêndio subterrâneo em turfa, que pode gerar esterilização do solo, pode causar danos irreversíveis. Logo, realizar estudo a partir de queimadas controladas, ou seja, provocadas pelo próprio homem para fins de estudo, pode gerar uma grande perda para o meio ambiente o que dificulta a pesquisa na área.

Os padrões de combustão e propagação da queima da turfa apresentam comportamento similar em diversos locais do mundo, possibilitando assim, pré-estabelecer o comportamento deste tipo de incêndio. Os padrões do comportamento da queima em turfa observados com o radiômetro T4MAX apresentaram também os mesmos padrões. Desta forma, após a detecção seria possível realizar estudos de monitoramento do incêndio por si só, bem como ao longo do tempo para avaliar os danos causado ao ecossistema local.

O emprego do radiômetro T4MAX nas ações de detecção de focos de incêndio subterrâneo em turfas demonstrou ser de extrema importância para a detecção precisa. O objetivo de localizar os focos foi atingido, não somente para fins de estudo do ecossistema, mas as imagens geradas durante o sinistro geram uma informação relevante para os órgãos de resposta, pois a tomada de decisão pode ser mais rápida e eficiente para uma atuação das equipes que trabalham no combate ao incêndio no local.

Os resultados desta pesquisa geram a possibilidade de desenvolver outros estudos para ampliar o conhecimento sobre o assunto. O monitoramento do incêndio subterrâneo em turfa por câmera térmica portátil pode ser feito durante o combate a incêndio até sua extinção permitindo conhecer o comportamento do foco ao longo do tempo.

\section{REFERÊNCIAS BIBLIOGRÁFICAS}

ANDREJKO, M. J.; FIENE, F.; COHEN, A. D. Comparison of ashing techniques for determination of the inorganic content of peats. In: SYMPOSIUM ON TESTING OF PEATS AND ORGANIC SOIL 1982.Toronto. Proceedings. Toronto, ASTM, 1983.

AGUIAR, Ludimila Moura de Souza; CAMARGO, Amabílio José Aires de. Cerrado: ecologia e caracterização. Brasília: Embrapa, 2004.
BULLARD.T4MAX. Thermal Imager Bid Specifications. Cynthiana, KY. USA, 2013.

CHISTJAKOV, V.I.; et al. Measures for Fire-Prevention on Peat Deposits. In: Wein, R.W.; MacLean, D.A. The role fire in northern circumpolar ecosystems. USSR: SCOPE, 1983. Cap. 14, p.259-271.

COUILLARD, D.; Water Research, v.28, p.1261-1274, 1994.

DUGAN, P. Wetland Conservation. IUCN, 1990. 95p.

EITEN, G. Vegetação Natural do Distrito Federal. Brasília: Universidade de Brasília/SEBRAE, 2001. 162p.

INSTITUTO NACIONAL DE METEREOLOGIA. Página consultada em 24 de setembro de 2014, $<$ http://www.inmet.gov.br>

INSTITUTO DE PESQUISAS TECNOLÓGICAS DO ESTADO DE SÃO PAULO. Estudo das possibilidades de aproveitamento de turfa no Estado de São Paulo. São Paulo, IPT, 1979. (Relatório 12.761)

JENSEN, J.R. Sensoriamento remoto do ambiente: uma perspectiva em recursos terrestres. São José dos Campos: Parêntese, 2009. 604 p.

ORGANIZAÇÃO DAS NAÇÕES UNIDAS PARA A EDUCAÇÃO, CIÊNCIA E CULTURA. Vegetação do Distrito Federal: tempo e espaço. - 2.ed. - Brasília: UNESCO, 2002. 80p

REIN, G.et al. The severity of smouldering peat fires and damage to the forest soil. Catena. 74 (3), p.304-309, 2008.

USUP, A. et al. Combustion and thermal characteristics of peat fire intropical peatland in Central Kalimantan,Indonesia. Tropics. V. 14(1), 2004. 